\title{
PENGARUH KEPEMIMPINAN DAN KEPUASAN KERJA TERHADAP KINERJA KARYAWAN MELALUI MOTIVASI KARYAWAN LKP LESTARI KOMPUTER SLAWI
}

\author{
Sri Lestari dan Joko Mariyono \\ LKP Sri Lestari dan Universitas Pancasakti Tegal \\ Srilestarislw18@gmail.com
}

\begin{abstract}
Employee Performance is one of factors as the determiner to improve the quality of students. Thus, employee performance should get the attention and support seriously from any sides, especially from component of human resources institution. The expectation is it will improve the motivation of employee that impact on the result of the students' achievement. The goals of the research are (1) to desrcibe the leadership, job satisfaction, motivation and employee performance, (2) to know the influnces of leadership and job satisfaction toward employee motivation, (3) to know the influences of leadership and job satisfaction toward employee performance, (4) to know the influences of motivation toward employee performance, (5) to know the influnces of leadership and job satisfaction toward performance through employee motivation. The participants in this research are 37 people. These participants are the employee of LKP Lestari Komputer Slawi. The data is analyzed by Structural Equation Modeling (SEM) using AMOS 18.00 as analysis tool. The results of Standardized Regression Coefficient were shown that the leadership and job satisfaction has influenced significantly on the employee motivation (0,27), job satisfaction toward employee satisfaction (0,55), leadership toward employee performance $(0,41)$, job satisfaction toward employee performance $(1,00)$. The results of p-value were also shown that motivation has influenced toward employee performance $(<0,001)$.
\end{abstract}

Keywords : leadership, satisfactory, motivation, and performance

\section{PENDAHULUAN}

Kinerja yang baik dan profesional oleh segenap karyawan (perusahaan) atau pegawai (organisasi/dinas pemerintah) adalah salah satu tujuan manajemen SDM. Manajer atau pimpinan melalui kualitas kepemimpinannya adalah salah satu faktor penentu keberhasilan manajemen SDM. Kepemimpinan yang efektif sangat dipengaruhi oleh kepribadian pemimpin. Setiap pemimpin perlu memiliki aspek- aspek kepribadian yang dapat menunjang usahanya dalam mewujudkan hubungan manusia yang efektif dengan anggota organisasinya (Yukl, 2005).

Kesuksesan atau kegagalan suatu organisasi ditentukan oleh banyak hal, yang salah satunya adalah kepemimpinan yang berjalan dalam organisasi tersebut. Pemimpin yang sukses adalah apabila pemimpin tersebut mampu menjadi pencipta dan pendorong bagi 
bawahannya dengan menciptakan suasana dan budaya kerja yang dapat memacu pertumbuhan dan perkembangan kinerja karyawan atau pegawai yang dipimpinnya. Pemimpin tersebut memiliki kemampuan untuk memberikan pengaruh positif bagi karyawan atau pegawai untuk melakukan pekerjaan sesuai dengan yang diarahkan dalam rangka mencapai tujuan yang ditetapkan. Kemampuan dan cara-cara dalam memimpin inilah sering disebut dengan gaya kepemimpinan.

Gaya kepemimpinan diartikan sebagai perilaku atau cara yang dipilih dan dipergunakan pemimpin dalam mempengaruhi pikiran, perasaan, sikap, dan perilaku organisasinya. Gaya kepemimpinan adalah cara seorang pemimpin mempengaruhi perilaku bawahan, agar mau bekerja sama dan bekerja secara produktif untuk mencapai tujuan organisasi secara rela tanpa merasa terpaksa/dipaksakan. Gaya kepemimpinan akan langsung bersinggungan dengan para karyawan sebagai pihak yang dipimpin, terutama dari aspek psikologis para karyawan.

Seorang pimpinan harus mampu memberikan petunjuk dan pengawasan, meningkatkan kemauan karyawan, dalam hal ini tenaga pendidik dan kependidikan, membuka komunikasi dua arah, dan mendelegasikan tugas. Pemimpin dan karyawan merupakan elemen penting dalam perusahaan yangmemiliki peran penting dalam menjalankan sebuah perusahaan. Dewasa iniperkembangan bisnis yang semakin pesat dan tingkat persaingan yang semakin tajam membuat perusahaan harus meningkatkan dan mengembangkan performancenya di semua bidang. Setiap perusahaan memiliki cara agar perusahaannya dapat bertahan ditengah- tengah persaingan yang ketat, salah satunya bidang yang harus ditingkatkan ialah sumber daya manusia.
Hal ini dilakukan agar perusahaan tetap bertahan dalam persaingan global. Karyawan mrupakan aset perusahaan

yang diharapkan dapat bekerja secara optimal guna menunjang kesuksesan perusahaan.

Faktor lain yang berpengaruh dalam kinerja karyawan adalah kepuasan kerja. Kepuasan kerja merupakan salah satu faktor penting yang mempengaruhi kinerja karena sebagian besar waktu manusia dihabiskan di tempat kerja.

Robbins (2008) menyatakan bahwa kepuasan kerja adalah sikap umum terhadap pekerjaan seseorang sebagai perbedaan antara banyaknya imbalan yang diterima pekerja dan banyaknya yang diyakini yang seharusnya diterima. Kepuasan kerja juga dipengaruhi oleh fungsi dan kedudukan karyawan dalam organisasi. Karyawan pada level bawah lebih besar kemungkinan yang mengalami ketidakpuasan dan kebosanan karena pekerjaan yang kurang menantang dan tanggung jawab yang kecil. Hal ini bisa terjadi pada karyawan pada level bawah yang berpendidikan tinggi yang memperoleh pekerjaan yang tidak sepadan dengan kemampuan keahliannya. Banyak faktor yang dapat mempengaruhi kinerja, salah satunya adalah yang menyangkut dengan tingkat kepuasan dalam bekerja.

Faktor lain yang menyebabkan peningkatan kinerja karyawan adalah motivasi. Motivasi merupakan sebab, alasan dasar, pikiran dasar, gambaran dorongan seseorang untuk berbuat atau ide pokok yang berpengaruh besar sekali terhadap segenap tingkah laku manusia. Motivasi tidak hanya berwujud kebutuhan ekonomis yang bersifat materil saja (berbentuk uang) akan tetapi motivasi karyawan juga dipengaruhi oleh faktorfaktor akan keberhasilan pelaksanaan pegawai dalam bekerja, pengakuan akan 
keberhasilan dalam bekerja, tanggung jawab, dan pengembangan karyawan.

Faktor selanjutnya yang dapat meningkatkan kinerja karyawan adalah motivasi. Seorang karyawan dapat bekerja secara profesional jika pada dirinya terdapat motivasi yang tinggi. Karyawan yang memiliki motivasi yang tinggi biasanya akan melaksanakan tugasnya dengan penuh semangat dan enerjik, karena ada motif-motif atau tujuan tertentu yang melatarbelakangi tindakan tersebut. Motif itulah sebagai faktor pendorong yang memberi kekuatan kepadanya, sehingga ia mau dan rela bekerja keras. Hal itu dibuktikan berdasarkan hasil penelitian Mc.Cleland (1961), Edward Murray (1957), Miller dan Gordon W (1967) yang dikutip Mangkunegara (2005), menyimpulkan bahwa ada hubungan yang positif antara motivasi dengan pencapaian kinerja/prestasi kerja. Artinya pimpinan maupun karyawan yang mempunyai motivasi berprestasi tinggi akan mencapai kinerja yang tinggi, dan sebaliknya mereka yang kinerjanya rendah disebabkan karena motivasi kerjanya rendah.

Motivasi kerja seorang karyawan akan menjadi rendah jika apa yang diperolehnya tidak sesuai dengan apa yang dikerjakannya. Karyawan membutuhkan kebutuhan sosial, teman, afiliasi, interaksi, dicintai dan mencintai, serta diterima dalam pergaulan kelompok pekerja dan masyarakat lingkungannya, karyawan juga mempunyai kebutuhan akan penghargaan dirinya serta mengatualisasikan dirinya sehingga dapat diterima di lingkungan sosialnya. (Mangkunegara, 2005).

\section{Tujuan Penelitian}

Berdasarkan permasalahan penelitian yang telah ditentukan, maka tujuan penelitian adalah untuk :
1) Mengetahui deskripsi kepemimpinan, kepuasan kerja, motivasi dan kinerja karyawan di LKP Lestari Komputer Slawi.

2) Mengetahui seberapa besar pengaruh kepemimpinan dan kepuasan kerja terhadap motivasi karyawan di LKP Lestari Komputer Slawi.

3) Mengetahui seberapa besar pengaruh kepemimpinan dan kepuasan kerja terhadap kinerja karyawan di LKP Lestari Komputer Slawi.

4) Mengetahui seberapa besar pengaruh motivasi terhadap kinerja karyawan di LKP Lestari Komputer Slawi.

5) Mengetahui seberapa besar pengaruh kepemimpinan, kepuasan kerja terhadap kinerja melalui motivasi karyawan di LKP Lestari Komputer Slawi

\section{Model Kerangka Berpikir}

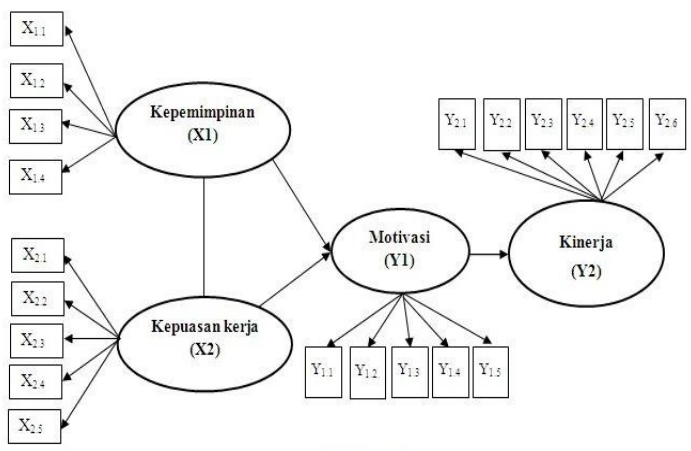

\section{METODE PENELITIAN}

\section{Jenis Penelitian}

Berdasarkan teknik analisis data yang dilakukan, penelitian ini merupakan penelitian kuantitatif. yaitu ilmu yang valid, ilmu yang dibangun dari data empiris, teramati, terukur, menggunakan logika matematika dan membuat generalisasi. Selain ingin mendapatkan gambaran tentang kepemimpinan, kepuasan, motivasi, dan kinerja karyawan LKP Lestari Komputer Slawi, penelitian ini 
juga ingin mendapatkan gambaran tentang pola hubungan dan pengaruh dari variabel-variabel penelitian tersebut. Mengacu pada tujuan penelitian, maka metode yang digunakan dalam penelitian ini adalah metode deskriptif dan verifikatif.

\section{Populasi dan Sampel Penelitian}

Populasi dalam penelitian ini adalah karyawan LKP Lestari Komputer Slawi yang berjumlah 37 orang. Sesuai pandangan Arikunto tersebut, karena jumlah populasi relatif kecil yaitu kurang dari 100 orang, maka penulis memilih menggunakan studi populasi, artinya semua sampel merupakan populasi. Dengan metode ini diharapkan hasilnya dapat lebih mendekati nilai sesungguhnya dan dapat memperkecil terjadinya penyimpangan terhadap nilai populasi.

\section{Metode Analisis Data}

Alat Analisis yang digunakan dalam penelitian ini adalah analisis jalur SEM

\section{HASIL PENELITIAN}

\section{Hasil Uji Validitas}

Berdasarkan pengujian validitas, menunjukkan bahwa untuk variabel kepemimpinan, kepuasan kerja, motivasi kerja dan kinerja karyawan terdiri dari bebera pertanyaan kemudian diujikan validitasnya kepada 37 orang responden, dan pertanyaan untuk variabel-variabel tersebut sudah valid karena memiliki nilai korelasi di atas rtabel sebesar 0,325

\section{Tabel 1}

Hasil Uji Reliabilitas Kepemimpinan

$$
\begin{array}{ll|l|l|}
\multicolumn{3}{l}{\text { Reliability Statistics }} \\
\text { Cronbach's } & \begin{array}{l}
\text { Cronbach's Alpha } \\
\text { Based on } \\
\text { Standardized Items }
\end{array} & \begin{array}{l}
\mathrm{N} \text { of } \\
\text { Items }
\end{array} \\
0,800 & 0,811 \mid
\end{array}
$$

Dari hasil perhitungan reliabilitas instrument variabel kepemimpinan diperoleh nilai reliabilitas sebesar 0,800 Instrument variabel penelitian dikatakan reliabel apabila nilai $\alpha>0,6$. Karena nilai cronbach's alpha variabel kepemimpinan kepala sekolah sebesar 0,800> 0,6 maka kuesioner tentang kepemimpinan dikatakan reliabel.

Tabel 2

\begin{tabular}{|c|c|c|}
\hline & Reliability Statistics & \\
\hline $\begin{array}{l}\text { Cronbach's } \\
\text { Alpha }\end{array}$ & $\begin{array}{l}\text { Cronbach's Alpha } \\
\text { Based on } \\
\text { Standardized Items }\end{array}$ & $\begin{array}{l}\mathrm{N} \text { of } \\
\text { Items }\end{array}$ \\
\hline 0,875 & 0,888 & 10 \\
\hline
\end{tabular}

Hasil Uji Reliabilitas Kepuasan Kerja

Dari hasil perhitungan reliabilitas instrument variabel kepuasan kerja diperoleh nilai reliabilitas sebesar 0,875 . Instrument variabel penelitian dikatakan reliabel apabila nilai $\alpha>0,6$. Karena nilai cronbach's alpha variabel motivasi kerja sebesar 0,875>0,6 maka kuesioner tentang kepuasan kerja dikatakan reliabel.

Tabel 3

Hasil Uji Reliabilitas Motivasi Kerja

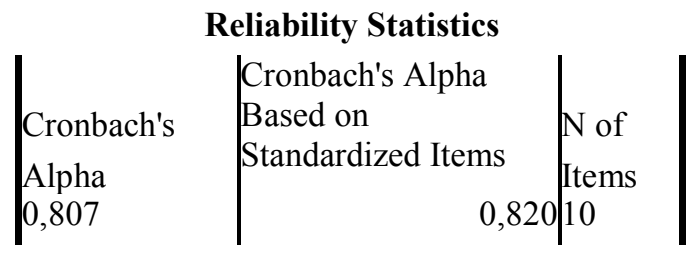

Dari hasil perhitungan reliabilitas instrument variabel motivasi kerja diperoleh nilai reliabilitas sebesar 0,807 Instrument variabel penelitian dikatakan reliabel apabila nilai $\alpha>0,6$. Karena nilai cronbach's alpha variabel motivasi kerja sebesar 0,807>0,6 maka kuesioner tentang motivasi kerja dikatakan reliabel. 
Tabel 4

Hasil Uji Reliabilitas Kinerja

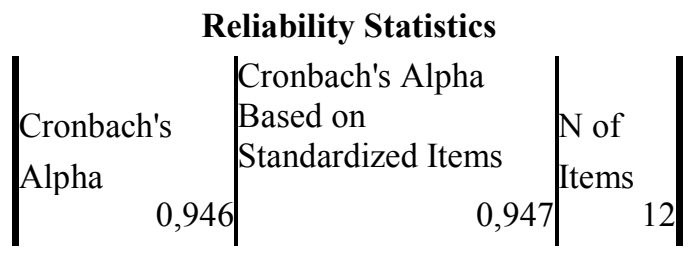

Dari hasil perhitungan reliabilitas instrument variabel kinerja diperoleh nilai reliabilitas sebesar 0,946 Instrument variabel penelitian dikatakan reliabel apabila nilai $\alpha>0,6$. Karena nilai cronbach's alpha variabel kinerja sebesar 0,946> 0,6 maka kuesioner tentang kinerja dikatakan reliabel.

Hasil analisis SEM dari penelitian ini dijabarkan dalam langkah pengujian hipotesis sebagai berikut:

\section{Pengujian Hipotesis 1}

$\mathrm{H}_{1}$ : Terdapat pengaruh antara kepemimpinan dan kepuasan kerja terhadap motivasi kerja karyawan LKP Lestari Komputer Slawi.

Adapun hasil analisis SEM yang dilakukan diuraikan dalam gambar di bawah ini :

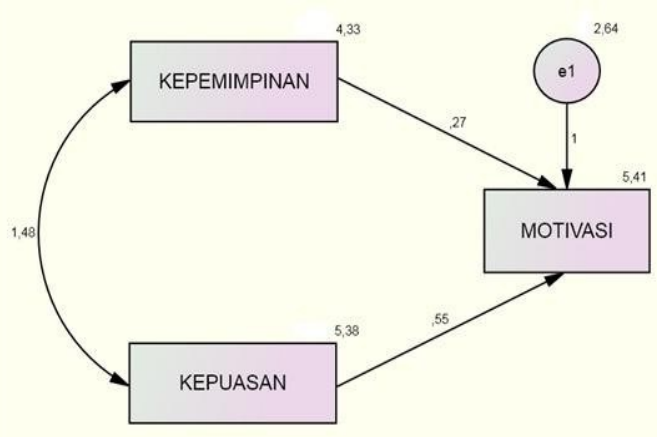

Pada gambar di atas dapat dijelaskan bahwa nilai koefisien regresi terstandar (beta) Kepemimpinan (X1) terhadap Motivasi Kerja(Y1) memperoleh nilai sebesar 0,27, sedangkan Kepuasan Kerja (X2) terhadap Motivasi
Kerja (Y1) memperoleh nilai sebesar 0,56. Dari nilai kedua koefisien ini dapat disimpulkan bahwa variable kepuasan kerja lebih penting dalam mempengaruhi motivasi kerja karyawan dibandingkan dengan variabel kepemimpinan.

\section{Pengujian Hipotesis 2}

$\mathrm{H}_{2}$ : Terdapat pengaruh antara Kepemimpinan dan Kepuasan Kerja terhadap Kinerja Karyawan LKP Lestari Komputer Slawi.

Adapun hasil analisis SEM yang dilakukan diuraikan dalam gambar di bawah ini :

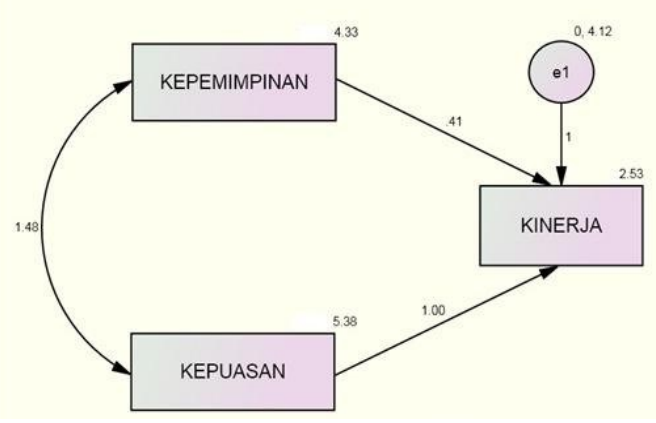

Pada gambar di atas dapat dijelaskan bahwa nilai koefisien regresi terstandar (beta) Kepemimpinan (X1) terhadap Kinerja Karyawan memperoleh nilai sebesar 0,41, sedangkan Kepuasan Kerja (X2) terhadap Kinerja Karyawan memperoleh nilai sebesar 1,00. Dari nilai kedua koefisien ini dapat disimpulkan bahwa variable Kepuasan Kerja lebih penting dalam mempengaruhi Kinerja Karyawan, dibandingkan dengan variable Kepemimpinan.

\section{Pengujian Hipotesis 3}

H3 : Terdapat pengaruh antara Motivasi terhadap Kinerja Karyawan LKP Lestari Komputer Slawi.

Adapun hasil analisis SEM yang dilakukan diuraikan dalam gambar di bawah ini : 


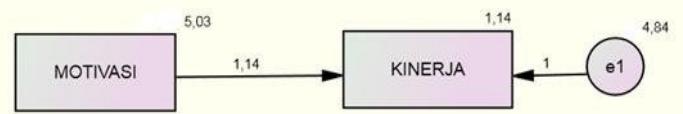

Pada gambar di atas dapat dijelaskan bahwa nilai koefisien regresi terstandar (beta) Motivasi Kerja (Y1) terhadap Kinerja Karyawan (Y2) memperoleh nilai sebesar 1,14.

\section{Pengujian Hipotesis 4}

H4: Terdapat pengaruh antara Kepemimpinan dan Kepuasan Kerja terhadap Kinerja Karyawan melalui Motivasi Kerja Karyawan LKP Lestari Komputer Slawi.

Adapun hasil analisis SEM yang dilakukan diuraikan dalam gambar di bawah ini :

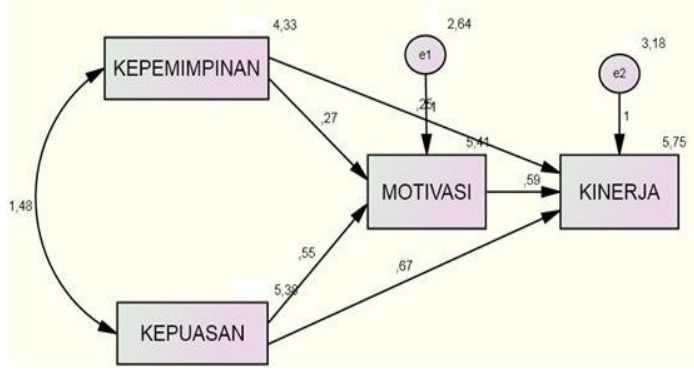

Pada gambar di atas dapat dijelaskan bahwa nilai koefisien regresi terstandar (beta) Kepemimpinan (X1) dan Kepuasan Kerja (X2) terhadap Kinerja Karyawan (Y2) melalui Motvasi Kerja Karyawan (Y1) memperoleh nilai sebesar 0,59.

\section{KESIMPULAN}

Setelah dilakukan hasil analisis dan pengujian terhadap hipotesis yang diujikan,maka diambil kesimpulan : (1) Kepemimpinan LKP Lestari Komputer Slawi menunjukkan kepemimpinan yang tinggi dilihat dari rata-rata indeks variabel kepemimpinan yakni sebesar 83,1\%. Kepuasan karyawan LKP Lestari
Komputer Slawi menunjukkan kepuasan yang tinggi dilihat dari rata-rata indeks variabel kepuasan yakni sebesar 76,9\%. Kinerja karyawan LKPLestari Komputer Slawi menunjukkan kinerja yang tinggi dilihat dari rata-rata indeks variabel kinerja yakni sebesar 77,98\%. Motivasi karyawan LKP Lestari Komputer Slawi menunjukkan kepuasan yang tinggi dilihat dari rata-rata indeks variabel motivasi yakni sebesar 77,98\%. (2) Kepemimpinan dan kepuasan kerja berpengaruh secara signifikan terhadap Motivasi karyawan. Hal tersebut dibuktikan dari nilai koefisien regresi terstandar (beta) kepemimpinan (X1) terhadap motivasi karyawanmemperoleh nilai sebesar 0,56 dan kepuasan kerja $\left(\mathrm{X}_{2}\right)$ terhadap motivasi kerja karyawan memperoleh nilai sebesar 0,24 . (3) Kepemimpinan dan kepuasan kerja berpengaruh secara signifikan terhadap kinerja karyawan LKP Lestari Komputer Slawi. Hal tersebut dibuktikan dari nilai karyawan memperoleh nilai sebesar 0,12, kepuasan kerja (X2) terhadap kinerja karyawan memperoleh nilai sebesar 0,39. (4) Motivasi berpengaruh secara signifikan terhadap kinerja karyawan LKP Lestari Komputer Slawi. Hal tersebut dibuktikan dari hasil pvalue berupa tiga buah tanda asterisk $(* * *)$, yang berarti nilai $\mathrm{p}$-value sangat kecil $(<0,001)$, maka dengan demikian bahwa hipotesis yang menyatakan terdapat pengaruh antara motivasi terhadap kinerjakaryawan LKP Lestari Komputer Slawi terbukti kebenaraanya. (5) Kepemimpinan dan kepuasan kerja berpengaruh secara signifikan terhadap kinerja melalui motivasi karyawan LKP Lestari Komputer Slawi. Hal tersebut dibuktikan dari hasil $p$-value berupa tiga buah tanda asterisk $(* * *)$, yang berarti nilai p-value sanggat kecil $(<0,001)$, maka dengan demikian bahwa hipotesis yang menyatakan terdapat pengaruh antara kepemimpinan dan kepuasan 
kerja terhadap kinerja karyawan melalui

Komputer Slawi terbukti kebenarannya. motivasi karyawan LKP Lestari

\section{DAFTAR PUSTAKA}

Anoraga Panji, 2006. Psikologi Kerja. Jakarta. Rineka Cipta.

Arikunto, Suharsimi. 2010. Prosedur Penelitian: Suatu Pendekatan Praktik. Jakarta: Rineka Cipta.

Annisa Pratiwi, 2014, Pengaruh Motivasi dan Disiplin Kerja Terhadap Kinerja Pegawai (Studi Pada PT. Telekomunikasi Ind, Tbk Wilayah Telkom Pekalongan), UNDIP Semarang.

Andri Budhi Nugroho, 2012, Pengaruh Motivasi dan Disiplin Kerja Terhadap Kinerja Karyawan Konveksi IV PT. DAN LIRIS di Suhkoharjo, Universitas Muhammadiyah Surakarta

Bryan Johanness Tampi (2014), Pengaruh Gaya Kepemimpinan dan Motivasi Terhadap Kinerja Karywan Pada PT Bank Negara Ind, TBK (Regional Sales Manado)

Ferdinand, Augusty, 2006. Metode Penelitian Manajemen: Pedoman Penelitian untuk Skripsi, Tesis dan Disertasi Ilmu Manajemen, Semarang: Badan Penerbit Universitas Diponegoro.

Gary, Dessler, 2008. Manajemen Sumber Daya ManusiaHuman Resource Management. Edisi 7. Jakarta: Indeks

Hasibuan, M. S. P., 2003. Manajemen Sumber Daya Manusia (Edisi Revisi). Jakarta: Bumi Aksara.

Handoko, T. Hani., 2003. Manajemen. Edisi 12, Yogyakarta: BPPE

Ida Ayu Brahmasari dan Agus Suprayetno, 2008, Pengaruh Motivasi Kerja, Kepemimpinan dan Budaya Organisasi Terhadap Kepuasan Kerja Karyawan Serta Dampaknya pada Kinerja Perusahaan, Universitas 17 Agustus Surabaya.

Luthans, Fred, 2006. Perilaku Organisasi. Edisi Sepuluh. Penerbit Andi. Yogyakarta.

Mangkunegara, Anwar Prabu, 2004. Manajemen Sumber Daya Manusia.Cetakan Pertama. Penerbit PT Remaa Rosdakarya. Bandung.

Mangkunegara, Anwar Prabu, 2005. Evaluasi Kinerja Sumber Daya Manusia.Edisi Pertama. Cetakan Pertama. Penerbit Refika Aditama. Bandung.

Meyta Indraswari, 2012. Pengaruh Budaya Organisasi Dan Motivasi Terhadap Kepuasan Kerja Dalam Mempengaruhi Kinerja Karyawan Kantor Unit PT Telkom Regional IV Semarang. Jurnal Manajemen dan Kewirausahaan

Robbins, Stephens P, 2006, PerilakuOrganisasi, Edisi ke Sepuluh, Prehallindo, Jakarta.

Prawirosentono, Suyadi, 1999. Kebijakan Kinerja Karyawan. Yogyakarta: BPFE. 
Rani Mariam, 2009, Pengaruh Gaya Kepemimpinan dan Budaya Organisasi Terhadap Kinerja Karyawan Melalui Kepuasan Kerja Karyawan Sebagai Variabel Interverning, UNDIP Semarang.

Rivai, Veithzal, 2004. Kepemimpinan dan Perilaku Organisasi, Edisi Kedua. Jakarta: PT Rajagrafindo Persada.

Robbins, Stephen P. 2006. Perilaku Organisasi. PT. Indeks Kelompok Gramedia. Jakarta.

Robbins, Stephen P. \& Judge Timothy A., 2013. Perilaku Organisasi. Jakarta: Salemba Empat.

Simamora, Henry, 2004. Manajemen Sumber Daya Manusia. Edisi Ke-3. Yogyakarta: STIE YKPN.

Siagian, Sondang P., 2002. Kiat Meningatkan Produktivitas Kerja. Jakarta: Rineka Cipta.

Sonnia Indah Putri, 2014, Pengaruh Gaya Kepemimpinan dan Loyalitas Karyawan Terhadap Kinerja Karyawan Pada PT Kurnia Alam Perista Kudus, UNDIP Semarang

Sugiyono, 2014. Statistika Untuk Penelitian. Bandung: Alfabeta.

Sunarto dan Djumadi Purwoatmodjo, Pengaruh Gaya Kepemimpinan Berbasis Madrasah (MBS) dan Iklim Organisasi Terhadap Kepuasan Kerja dan Kinerja Guru SMP di Wilayah Sub Rayon 04 Kabupaten Demak. ISSN : 14411-1799

Sutanto, Eddy Madiono, Peranan Gaya Kepemimpinan yang Efektif dalam Upaya Meningkatkan Semangat dan Kegairahan Kerja Karyawan di Toserba Sinar Mas Sidoarjo. http://puslit.petra.ac.id/journals/manage ment/

Sukrisna, Hendra. 2013. Pengaruh Motivasi Kerja, Supervisi Kepala Sekolah, Dan Kesejahteraan Terhadap Kinerja Guru Sekolah Dasar Di Kecamatan Sukoharjo Kabupaten Sukoharjo. Oline. www.portalgaruda.org.

Thoha, Miftah, 1983. Perilaku Organisasi; Konsep Dasar dan Aplikasinya, Edisi 1. Jakarta: PT RajaGrafindo Persada.

Yukl, Gary, 2005. Kepemimpinan Dalam Organisasi, Edisi Kelima. Jakarta: PT Indeks. 